\title{
Knowledge and Risk Perception of Vulnerable Women on Zika Virus Infection at Primary Health Care Level in Brazil
}

Claudia Garcia Serpa Osorio-de-Castro ( $\square$ claudiaosorio.soc@gmail.com )

Escola Nacional de Saude Publica - Sergio Arouca https://orcid.org/0000-0003-4875-7216

Cláudia Du Bocage Santos-Pinto

Instituto Integrado de Saude - UFMS

Clarice Antunes de Lima

School of Pharmacy, Fluminense Federal University

Elaine Silva Miranda

School of Pharmacy, Fluminense Federal University

Research

Keywords: Zika virus, preparedness, health risk, Health Knowledge, Attitudes, Practice

Posted Date: September 25th, 2020

DOl: https://doi.org/10.21203/rs.3.rs-80053/v1

License: (c) (i) This work is licensed under a Creative Commons Attribution 4.0 International License. Read Full License

Version of Record: A version of this preprint was published at Global Public Health on September 6th, 2021. See the published version at https://doi.org/10.1080/17441692.2021.1953106. 


\section{Abstract}

\section{Background}

The ZIKV infection outbreak in Brazil surged from late 2014, peaking in 2015. Vulnerable low-income groups, with inadequate housing conditions or sanitation were most affected by ZIKV-related neurologic syndrome. We aim to detect basal knowledge and beliefs, as well as knowledge gaps among vulnerable women.

\section{Methods}

A cross-sectional study was carried out in two low-income urban community settings: a small municipality in the Center West with few ZIKV infection cases and a large municipality in the Southeast hard-hit by the epidemic. We developed an open-ended data collection instrument centered on awareness of ZIKV infection, sources of information, possible causes, symptoms, risk perception and consequences for pregnant women, and applied it to vulnerable women after informed consent. Interviews were recorded, transcribed and content coded for thematic analysis.

\section{Results}

Seventy-nine women responded. The majority had some knowledge of the disease, its causes and consequences but distanced themselves from ZIKV infection. Health services in both communities did not respond adequately and did not contribute to communicate risk for women and children.

\section{Conclusions}

In an uncertain future scenario as to reemergence of disease, we propose that awareness will be diminished and acquired knowledge lost. This is a great public health challenge that must be overcome to prepare both vulnerable groups and the health system for public health emergencies.

\section{Background}

A disaster can be seen as a consequence of socially structured risks [1]. This is true for Zika virus infection, a neglected disease with climate-sensitive vectors for which spread initially went unchecked, beginning in poor and remote communities [2]. While on the one hand poverty is a factor that favors the occurrence of a disaster, on the other hand the disaster itself brings new risk situations for the exposed, mostly the most vulnerable ones.

The ZIKV infection outbreak in Brazil surged from late 2014, peaking in 2015. Poverty-stricken population groups were the most affected by Zika. Most cases of ZKV-related neurologic syndrome, with microcephaly, were detected among newborns coming from this type of environment. The most affected region was the Northeast, but states in the Southeast were also prone, due to large number of cases in poor vulnerable low-income communities in major cities [3]. 
Thus, social and economic vulnerability is a factor to be considered through such situations in the public health context, since the lack of information and inadequate perception of disease risk can be decisive factors for prevention and health promotion aimed at vulnerable groups.

Risk perception should include a variety of aspects of an individual, such as their cultural and social factors regarding the disease and its consequences and should be understood so that important measures can be developed regarding the health sector, considering the possibility of new ZKV epidemic.

This study was based on the assumption that poverty-stricken populations are most vulnerable and especially susceptible to health emergencies and disasters [4]. We investigated vulnerable women in two distinct Brazilian settings - one that was hard-hit by the epidemic, and another where cases where few and sparse.

Although risk perception has been studied in vulnerable groups during the epidemic [5], no previous work has been done to detect risk perception and knowledge among vulnerable women in non-epidemic seasons in Brazil, or to compare these aspects among different at-risk groups. Our aim is to help detect basal knowledge and beliefs, as well as important knowledge gaps in order to prepare the health system to deal with vulnerable groups in future public health emergencies.

\section{Methods}

This was a cross-sectional study, carried out in two different low-income urban community settings in Brazil: a small municipality in Center West Brazilian state, where ZIKV infection cases were few $(1,719)$, and a large municipality in a state of Southeast Brazil, where number of ZIKV infection cases were many $(68,542)$ and the toll in microcephaly and ZIKA Neurologic Syndrome was high. The same time-window for number of cases was used [3], from late 2014 to late 2016.

Preliminary analytical categories were established, based on known consequences of ZIKV infection, risk communication and risk perception literature [6] and The WHO Resource Pack [7] which can be used in communities with Zika virus transmission or those at risk. It is a structured survey instrument and deals with the entire scope of Knowledge, Attitudes and Practices (KAP) about Zika virus, being perceived as a means to gather valuable information. An open-ended data collection instrument was developed. Questions centered on awareness of ZIKV infection, possible causes, symptoms, sources of information on the disease, risk perception and risk factors, and possible consequences for pregnant women.

The two researched areas are different in respect to demographic dimensions and social environment. The population in the large urban municipality totaled 6,718,903 inhabitants in 2019 (second in the country) and the women came from an urban slum (favela), in which social exclusion and urban violence are recognized characteristics. The population in the smaller municipality in Brazil's heartland totaled 57,665 inhabitants in 2019, ranking 717th in population among 5,570 Brazilian municipalities [8]. Women were mostly poor but were not exposed to the same external factors as the women from the large municipality. 
Final number of interviews was given by data saturation. In the Center West municipality, thirty-nine adult women at all eight urban Primary Health Care (PHC) centers were interviewed, in April 2018. In the Southeast, forty adult women attending a large PHC, were interviewed from July to September 2018. All interviewees were asked for consent, according to Brazilian ethical guidelines [9]. No censorship regarding age distribution in adult population or other demographic characteristics was applied. Vulnerability of interviewees was characterized by membership in Brazilian government income supplementation programs, number of children, number of persons in household, number of employed persons in household.

All interviews were recorded and transcribed, and content analysis was performed, after in-depth reading of interviews, coding and detection of key-expressions and central ideas. The preliminary characteristics were revised, and new categories emerged. The women's speech was analyzed regarding principal and subcategories and highlighted by the risk perception and knowledge on ZIKV literature.

The study was sanctioned by the Sergio Arouca National School of Public Health Ethics Review Board under CAAE 67311617.8.0000.5240 (review number 2.180.892) on July 20th, 2017.

\section{Results}

Carefully approached for possible inclusion, the majority of women who were asked to participate accepted and gave informed consent. Many were eager to talk and exchange information. The initial intent was to interview 40 women from each setting, but one group only reached 39 women.

Regarding demographic characteristics, Table 1 summarizes findings. 
Table 1

Demographic characteristics of interviewees. Vulnerable women in Brazilian urban centers, 2018.

\section{Brazilian Urban Center/Region}

Southeast

(large urban center)

Number of interviewees

Demographic characterisitics

Age distribution
3

12

8

7

6

3

2.1

2.7

4.0

3.8

Average number of people with income in household

Number of recipients of income supplementation $1.7^{\mathrm{b}}$

13
Center West

(small urban center)
39

a - no demographic data for 1 interviewee; $b$ - data from 36 respondents

The majority of interviewees were in reproductive age, from 21 to $50 \mathrm{yrs}$. Number of children per family as number of people per household were 2.1 and 4.0 in the Southeast, and 2.7 and 3.8 in the Center West, respectively. More women from small municipalities were recipients of income supplementation.

Final principal categories were (i) general awareness of ZIKV infection (ii) specific knowledge about the disease (iii) risk perception (iv) perceived consequences for pregnant women. Table 2 presents results for the first category, with its sub-categories. 
Table 2

General awareness and specific knowledge about ZIKV infection. Vulnerable women in two Brazilian urban centers, 2018.

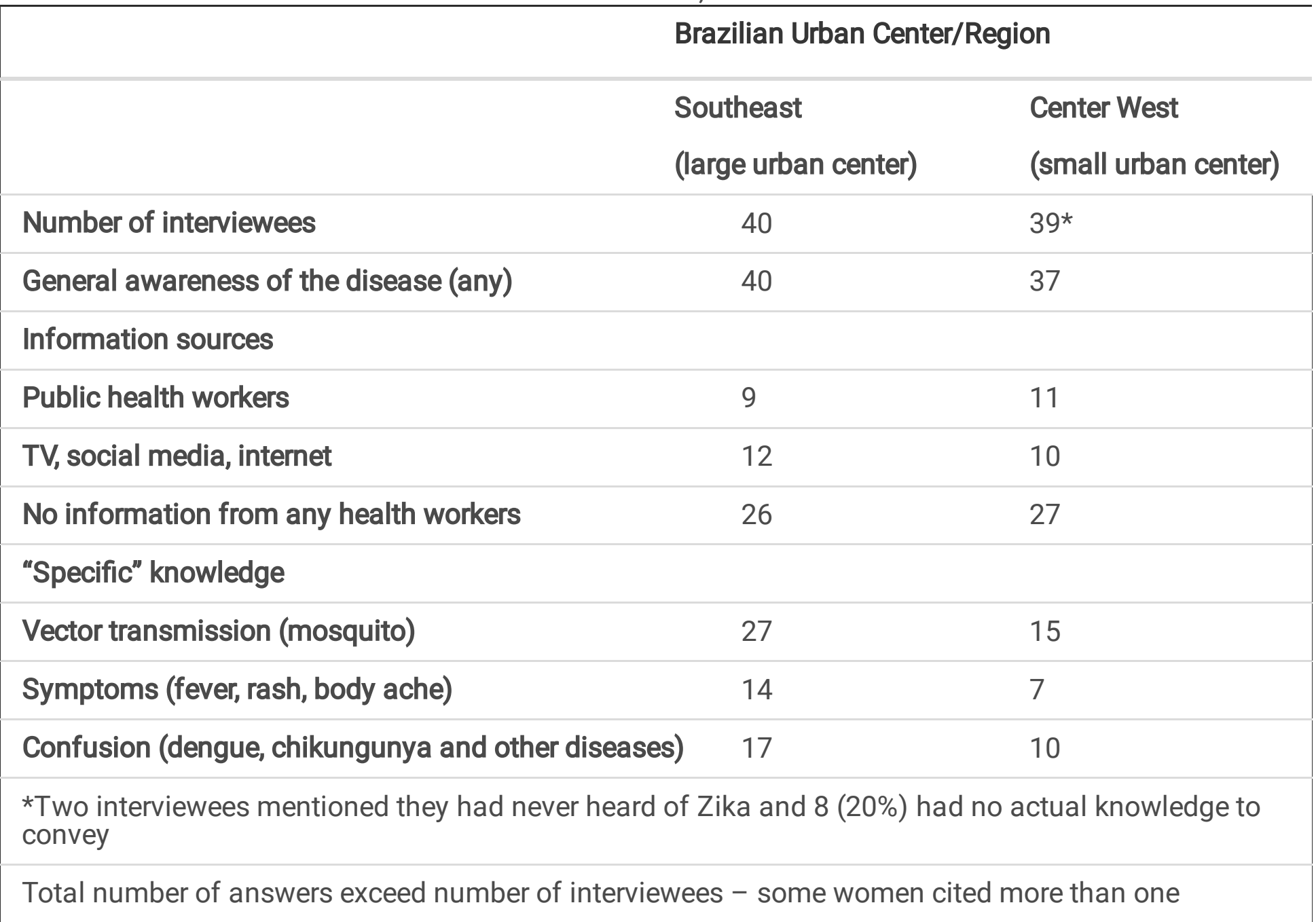

Except for two women in the smaller municipality, all others had some or any awareness of ZIKV or had heard about the disease.

As to general awareness, a highlight was the response to sources of information on ZIKV infection. Many interviewees pointed towards the media as a main source of information.

"What I know (...) and I'm into what they say on TV, right? Always only (about) microcephaly". (MS 37)

"So, I know (about the disease) from TV, right?" (MS 1)

When asked if they got any information from health workers, many responded with a simple 'no'. Information from health workers centered on elimination of mosquito nurseries.

(on information from health workers) "No, only to forewarn us, right, about zika. I can't remember (much) Ahhh from what I know, it's about plants, right? Watering plants, accumulating water, accumulated water in (discarded) tires right? This is what I know, right?" (MS 20). 
"Yes, you have to try to close down places where there are mosquito nurseries". (RJ 03)

Some mentioned that Zika had been 'forgotten'.

"Something very sad, something that will remain forever, and I don't know what became of it (the disease) right, because nobody comments on it anymore" (MS 31).

Association to mosquitos as vectors was present in the discourse of women, and more women in the Southeast associated Zika with mosquitoes.

"The cause (of ZIKV infection) is the mosquito, isn't it?" (RJ1)

"They're always talking (...) about the mosquito, right? What it's causing, right? About zika, the disease (...)"(MS 1)

Confusion was present in respect to the symptoms of the disease. The interviewer prompted the women in case they needed reminding that the focus of the questions was Zika.

"They say it's not like dengue, but it was. When it is going to rain your bones ache" (MS 21)

"It brings (with it) a lot of body ache, from the disease; it (the disease) causes lots of things, right? Body ache, a lot of fever; It even feels like the flu, right? In the beginning, it feels like a flu, but after it ends up more intense. Like malaria, right?" (MS 1)

Women mentioned factors associated to ZIKV infection. Table 3 summarizes distribution of answers by category and sub-categories. 
Table 3

Factors associated to ZIKV infection risk. Vulnerable women in two Brazilian urban centers, 2018.

\section{Urban Center/Region}

\section{Southeast}

(large urban center)
Center West

(small urban center)

Number of interviewees

40

39

Factors associated to risk of ZIKV infection

Environment (garbage, lack of sanitation, presence of mosquito)

Health status

Low Immunity

Chronic diseases

Poverty

Childhood

Old age

Does not know

Total number of answers exceed number of interviewees - some women cited more than one

Several responders associated ZIKV to problems with sanitation, lack of garbage collection and 'unclean' water. Most of all, risk was perceived as coming from outside, promoted by others.

"Oh, I think it's (ZIKV infection strikes) where there is less sanitation, people that do not clean their backyards, they don't worry. You can see that many people do not care at all". (MS 7)

"If everyone takes care, care for your backyard, and all that must be clean, I don't think you can (catch ZIKV infection)". (MS 10)

Some were very critical of their communities:

“(...) you take care of your home, but others do not. You're squeaky clean, everything is spotless, but not everyone is. In (neighborhood) everything is very dirty. You clean but others don't. Alleys are filthy, garbage, trash, lots of stuff. Sewage in the open. It (the filth) attracts, understand? Some people don't like to clean their own environment. It's difficult." (RJ 37)

"Beats me, I think people are untidy with their neighborhoods, there's a lot of garbage. Lots of garbage, lots of, how do you say it? 'Contaminated', right? Those contaminated things, do you get it? And when the 
garbage collector comes and takes it away, people go and throw more. Then come the flies, the blowflies. All that." (RJ 9)

Health status was a possible contributor to risk for ZIKV infection, especially regarding low immunity status.

“(...) from my point of view it depends on the person's health state. (...) if the person's health is fragile, I don't know, zika might be more serious than in a normal person, with normal health, I don't know. To me it can vary from person to person" (RJ 14)

"It depends on the body, right? On the person's immunity, I think, if it's very low, right? If for pregnant women, immunity is low, I think there is more risk". (MS 19)

Preexistent chronic diseases were also mentioned as a risk for ZIKV infection.

"Someone that has, I don't know, diabetes or some heart problem or hypertension (...). I suppose one thing drags the other" (MS 33)

"Oh, they (source of information) said whoever has a chronic disease, something. I imagine those (are more at risk)"(MS 21)

Poverty (seen as an impediment for private, costly care) was reported by only one respondent:

"Oh, surely the poor population, right? If you have the means to go to private physicians and others you can care better for your child. And those that are poorer can't because public health services are so deficient" (MS 9)

Finally, age - old or young - were factors associated to risk. A connection to low immunity and frailty underlies the discourse.

"I think elderly people are more prone to trouble, right? Because of low immunity, right?" (MS 16)

"Children and the elderly, I suppose, that are more sensitive, immunity is lower." (MS 33)

"And the elderly (...) they are more prone because they are weaker, right?" (RJ 19) 
Table 4

Perceived consequences for pregnant women. Vulnerable women in two Brazilian urban centers, 2018.

\begin{tabular}{|lll|}
\hline & \multicolumn{2}{l|}{ Brazilian Urban Center/Region } \\
\hline & $\begin{array}{l}\text { Southeast } \\
\text { (large urban } \\
\text { center) }\end{array}$ & $\begin{array}{l}\text { Center West } \\
\text { (small urban } \\
\text { center) }\end{array}$ \\
\hline Number of interviewees & 40 & 39 \\
\hline Perceived consequences & & \\
\hline $\begin{array}{l}\text { Problems associated to ZIKV infection during } \\
\text { pregnancy }\end{array}$ & 1 & 2 \\
\hline Abortion & 13 & 11 \\
\hline Non-specific problems in fetal development & 18 & 16 \\
\hline Deformities, malformation, Microcephaly & 8 & 6 \\
\hline Does not know & 18 & \\
\hline Total number of answers exceed number of interviewees - some women cited more than one
\end{tabular}

In both groups, only three among 79 women associated Zika with abortion or miscarriage.

"My little granddaughter, my daughter was pregnant, and she lost (the baby) right, her little girl because of this disease. Last year". (MS 10)

"It causes trouble, right, for the child, right? I don't know what can happen. I think she (the pregnant woman) can lose the child, something like that." (MS 16)

"(On what can happen) From an abortion, right, to a cephalic problem, right?" (RJ 20)

Non-specific problems with fetal development and the association of Zika infection in pregnancy with birth defects and microcephaly were abundantly mentioned.

"There are problems with the fetus." (RJ 04)

"It's because I saw cases of pregnant women (...) that had zika and babies were born with microcephaly" (MS 17)

"Well, what I know is that my daughter-in-law got pregnant, right? We were really worried about this because the child could be born with a deformity". (RJ 16)

"What's the name of the condition? Mic... I don't know...(babies) are born with a small head." (MS 37) Women reproduced various degrees of acknowledgement, from misinformation to accurate knowledge. 
"So, until the first three months (of pregnancy) she (the pregnant woman) is at risk for the fetus to be born with microcephaly, right? Or some problem with the fetus." (MS 13)

"Yes, everything goes to the baby, right? Everything there will go to the baby because it (the virus) can pass through the placental barrier." (MS 30)

In the discourses there was some non-categorized content, which is relayed below. Some women were suspicious as to the occurrence of Zika and its related consequences. A 28-year old woman with two small children volunteered that zika had been a 'lie':

“(..) that children are born with problems. I don't know, I think it's a lie (...) they are blaming this disease, but it (really) was an expired vaccine, something the pregnant woman took. I've heard so many stories I don't know anything anymore". (RJ 01)

Another questioned the information she received from the media:

"I heard about it on television, I don't know if it's true, but (it is) microcephaly, right?" (MS 36)

Some suspected causes for microcephaly other than a mosquito-borne viral infection, as relayed by one interviewee:

"I think it's not the poor mosquito that is responsible, right, for incidence of cases (...). Not all places have (mosquitos). Various friends had babies during this period, of this epidemic, zika epidemic, but it was very limited. I think something else caused it, right? Some drug for which the mothers produced an antibody and the child ended up with microcephaly." (MS 09)

Women also cited preventive measures, and the content of the discourse is clear:

"Including information, right? What the person can (do) at home (...) she decreases the chances by (adequate) habits, covering the water tank, these things we hear around (...). Always more hygiene in everything helps." (RJ 17)

\section{Discussion}

Main results of this study presented awareness, specific knowledge and perceptions on ZIKV infection, associated factors and consequences among vulnerable women in two distinct Brazilian regions, one in which number of Zika cases had been moderate and one in which cases were much higher in number. Compulsory notification began in 2016 [10] and from then to 2018, total number of cases in the Center West was 42,275 ( $17.49 \%$ of total number of cases in the country), while in the Southeast they totaled 98,139 (40.62\%). [3, 11]

Other qualitative studies have assessed knowledge, attitudes and practices of women at risk for of ZIKV infection in Brazil, and of those actually infected by ZIKV [5]. We assumed that differences in regional incidence and in direct contact with the Zika epidemic and its consequences, such as microcephaly, might 
return different perceptions among women with similar backgrounds [12]. Moreover, the epidemic has waned in the last three years, and it is worthwhile to explore which knowledge has survived and whether attitudes and perceptions to risk remain in vulnerable groups.

Demographic characteristics of both groups show some similarity, in respect to age distribution. Most women were of reproductive age [13]. This characterizes an adequate at-risk group for ZIKV infection during pregnancy. Older women, past reproductive age, belong to the same social group and may reproduce views in respect to pregnancy risk. Due to seniority, older women continue to shoulder responsibilities in their social groups and may translate broader perceptions [14]. Older women may also be sexually active, but this source of risk (sexual transmission) [15] was not explored in this study.

The number of children per household reflects fertility rates for both regions in 2018: 1.70 in the Southeast and 1.87 in the Center West [16]. Differences were small. The risk to a child in a given household may be more linked to mothers' or caregivers' risk perceptions. Smaller children may be especially at risk, because they are possibly kept at home with mothers or caregivers most of the time [15].

The average number of persons per household was similar between the urban centers, but variation was very different - in the large urban center, 1 to 8 people lived in the household, while in the smaller urban center, 1 to 18 people. Nonetheless, earnings came from very few contributors in households. Poor families with a large number of children are more socially vulnerable and this characteristic holds for both settings in this study. Fewer women from the larger municipality were recipients of income supplementation - an indicator which characterizes poverty-stricken households in Brazil - but proportions were similar (36\% versus $41 \%$, respectively) and both groups are socially vulnerable [17].

Given the overall positive response of interviewees as to any knowledge of Zika, it would be safe to say that these groups have heard about the infection at some point in time, and the media, especially television, is perceived as the main source of information. Paradoxically, health workers and health professionals were not regarded as a source of information from most women. In the large urban center, in fact, where many cases occurred and where the PHC personnel had most probably had some experience with diagnostics and effects, many respondents gave a straightforward 'no' to the question. In the smaller municipality, a woman pointed out that Zika had been forgotten. Both situations may point to the health system possibly abandoning an important task in risk reduction - neglecting information dissemination [18]. However, would this in any way be useful for a resurgence of the disease in the future? Would preparedness profit from lessons learned about Zika and its consequences? Koenig and colleagues argue that 'lessons learned' are not a valid scientific output in public health and disaster research [19], and that this term should be discarded. However, the role of information dissemination in disaster preparedness is more than proven [20] and there is no way to condone the health system in both settings from falling short of their responsibilities.

While on one hand there was lack of comprehensive information from the health system, on the other the presence of at least three other endemic arboviruses in the country (dengue, chikungunya and yellow 
fever) and a number of other endemic diseases (such as malaria, which came up in the discourse) led to a lot of confusion in regard to symptoms [20]. The actual consequences of this were not investigated, but may reflect on inappropriate care-seeking behavior, which might enhance risk.

As to transmission ('cause') of ZIKV infection, more women from the large urban center associated it to mosquitoes, having had greater contact with the epidemic and to its consequences. Also, most information coming from health workers centered only on that aspect. In Brazil, vector control has been the mainstay in Zika awareness campaigns, and there has been wide criticism of the narrow range of risk reduction strategies available to the population that lives in squalid conditions, with inadequate sanitation, water supply or garbage collection [21]. The interviewees were more than aware of this risk factor and it was prominent in the discourse. Most women felt that they did their 'bit' in preventing occurrence of mosquito nurseries while their neighbors did not. Women did not condition sanitation to government action. This may be viewed as positive - if regarded as empowerment - but in these cases since government action was basically null, the population overestimated its role - actually more of a burden - in preventing disease. This is an important aspect in social representations of the ZIKV epidemic [12].

Other health factors, such as perceived low immunity and chronic illnesses were expressed as possibly associated to risk, but from few respondents in both groups. Age - young or old - was also an issue to some, but always related in the discourse to low immunity or frailty. It is noteworthy to point out, however, that there is evidence that young children ( $<4$ years) are three times more susceptible to ZIKV infection than adult men, possibly because of daily exposure inside the household [15].

Health status of the interviewees was not investigated, but aspects that were mentioned are present in the general population, and these aspects are perceived as 'risky' conditions in common knowledge [12]. Moreover, women investigated in this study were not themselves affected by ZIKV infection. The ability to discern and interpret greater or lesser risk in ZIKV infection with any factor may be jeopardized by lack of personal experience; deciding what is risky or not risky involves the ability to accurately discriminate [22]. For example, some mentioned immunity, but none mentioned vaccination as a non-specific health measure. This has significance at this moment, as Brazil has been undergoing a measles outbreak and there is new evidence that measles may enhance susceptibility to other infectious diseases [23]. Protection from vaccination may be a health issue unperceived by these women.

Poverty is certainly a main factor associated to ZIKV infection and to consequences for the unborn child. Poor, vulnerable populations are at-risk for ZIKV infection [24] and women and children are especially so. However, among the respondents, poverty in itself was not seen as a factor associated to Zika. Poverty is, for this population, an almost natural state, and no other is known. The link or factor perceived as an impediment - associated to being poor - was the fact that private health care would be impossible. Discussing the theory of 'affect heuristics' Eiser and colleagues [22] point out that a positive (or not negative) experience will lead one to make a more relaxed judgement in respect to risk prevention. If most 
women do not view poverty as a basic threat to their lives, an evaluation of any future occurrence related to ZIKV infection and its consequences will not be viewed as poverty dependent.

Problems associated to Zika infection during pregnancy brought up abortion, problems in fetal development and deformities and microcephaly. Overall, most women mentioned one or more of these aspects. However, despite the media and other sources of information, $20 \%$ of women from a high-risk municipality and $15.4 \%$ of women at a low-risk site answered that they did not know. This shows an important gap in knowledge of the disease and its consequences among the most at-risk population for ZIKV infection [15].

Abortion is illegal in Brazil, and as such was never mentioned as a 'secondary' prevention strategy [25], but as a consequence of ZIKV infection. Access to reproductive health strategies are limited in several Latin American countries, but in Brazil, the MoH's Women's Health Program covers contraception and DST screening and treatment. In 2013 , the prevalence of contraceptive measures was around $75 \%$, but dealt with mostly with women with a stable partner [26]. In 2018, possibly also as a consequence of the ZIKV scare, prevalence of contraception had increased and 15 to 19-year old non-pregnant women in São Paulo presented $81.1 \%$ prevalence of contraception. Around one third had already had at least one pregnancy; $4 \%$ declared an abortion and $61 \%$ a child from an unplanned pregnancy [27].

Problems with fetal development and sequelae related to ZIKV infection during pregnancy dominated the answers, with $77.5 \%$ of women from the larger municipality and $69.2 \%$ of women from the smaller one voicing that concern. Microcephaly was the dominant part of the discourse. Although information on ZIKV consequences has focused on microcephaly, Zika Neurologic Syndrome (ZNS), oftentimes accompanied by microcephaly, but not always so, was not mentioned. Congenital ZIKV infection produces several abnormalities in neurodevelopment and may not be apparent at birth, either because it is not recognizable or because diagnosis may depend on unavailable technologies. This is more so in the smaller community, where access to highly complex care is certainly not as easy, but women from the larger at-risk group did not speak about it either. Findings apparent at birth may resolve in time, or children with this problem may only have their condition asserted later in age, or even after entering school [28]. This may explain why women did not mention ZNS. If no 'problem' is apparent, no problem exists. However, most will probably never receive accurate diagnosis and lower developmental scores presented by these children may be mistaken for any other dysfunction. Moreover, when these women do not express concern over this, they will not actively seek care for their children.

Among the interviewees there was some other misinformation and inaccurate assumptions regarding pregnancy risk restricted to the first trimester, and a supposed relation to the placental barrier as a cause for infection. Otherwise creant in the media and other reliable sources as to information received from other topics, some women were suspicious of the consequences and causes of ZIKV infection. Suspicions may be related to the excess of available information and from the 'fake news' epidemic faced by many societies - fabricated news, manipulated news, advertisements and irrelevant news, which contrast to 'sufficient' news, usually evidence-based and true, but which may not be adequately 
valued [29]. This is big challenge for health professionals to approach and clear, and for risk reduction strategies to reduce, which couples with the fact that few women cited preventive measures for ZIKV infection.

Despite our understanding that the interviewed women from both municipalities are part of the same context, subtle differences were not definable, and may exist. As some interviewees were not very forthcoming with their opinions and had to be gently prodded for details, we might have some distortions as to perceptions. In contrast, our findings as to lack of knowledge and lack of health service involvement in dissemination of information and risk reduction is corroborated by previous work among infected pregnant women in Brazil [5]. In 2018, at the beginning of field research, the epidemic was still a 'fresh' subject to many women and there was talk of an augmented risk for the 2018-2019 summer months in Brazil, which may have given the subject a perceived sense of importance. As that forecast fortunately did not hold, and because there is little evidence for the future path of this disease, other investigations in this vulnerable population may produce different results. In a future scenario with less information on the infection, its causes and consequences, we propose that awareness will be certainly diminished and acquired knowledge lost.

\section{Conclusion}

The story of ZIKV infection in Brazil is a known entity - an emerging disease, sensitive to climate change, burdening areas already presenting important inequities and environmental disparities. And, in this case, putting vulnerable women and children at greater, unacceptable, risk.

Women at some point distanced themselves from the causes and consequences of the disease. Health services in both communities did not respond adequately to the ZIKV menace and did not contribute in any considerable way to communicate risk for women and children, according to the interviewee's responses. This is a great public health challenge that must be overcome.

However, it is possible that this may not be a 'ZIKV problem' at all, but an overreaching one, and in this case must be dealt with by structural measures related to communities, in order to enhance resilience and response. Recognition of risk and risk-prevention measures must be disseminated. Adverse context, poverty and poor health conditions are overwhelming determinants for risk.

What have we learned from the ZIKV outbreak? No one knows whether, when or how ZIKV might be returning. But it is still with us (cases are still being reported) as may be other emerging and re-emerging diseases. Vulnerable groups in the country are not protected. If risk reduction measures are not implemented a new health emergency of magnitude may be around the corner.

\section{Abbreviations}

ZIKV: Zika virus 
KAP: Knowledge, Attitudes and Practices

PHC: Primary Health Care

MoH: Ministry of Health

ZNS: Zika Neurologic Syndrome

\section{Declarations}

\section{Ethics approval and consent to participate}

The study was approved by the ENSP/Fiocruz Ethics in Research Board (CAAE 67311617.8.0000.5240). All participants signed a participant consent document that assures their rights in the present study.

\section{Consent for publication}

Informed consent was obtained from all study participants, and the study was conducted in accordance with the Brazilian Ethics Legislation (Resolução CNS 466/2012; reference 9).

\section{Data availability and materials}

All interviews were transcribed, and the files kept by the researchers responsible for the study. In order to preserve the identity of the participants, access to this data is restricted. The data may be available upon request in specific cases but cannot be in any way otherwise used or divulged, in accordance with Brazilian Ethics Legislation (Resolução CNS 466/2012; reference 9) and relevant data protection laws.

\section{Competing interests}

The authors declare that they have no competing interests.

\section{Funding Sources}

This work was partially supported by the European Union's Horizon 2020 Research and Innovation Programme under ZIKAlliance Grant Agreement no. 734548 and by the Brazilian National Research and Development Council (CNPq), grant number 304975/2016-8). No funding source participated in planning, analyses or discussion of results.

\section{Authors' contributions}

CGSOC, CDBSP and ESM designed the analyses, analyzed the data and conducted the study. CDBSP and CAL carried out the interviews. CGSOC wrote the first draft of the manuscript. ESM, CDBSP and CAL critically reviewed the manuscript. All authors read and approved the final manuscript.

\section{Acknowledgements}


The authors most gratefully thank the PHC Services that received this field research in their midst. Although a proper thank you would involve disclosing identities of these services, naming them would breach confidentiality.

\section{References}

1. Rabby YW, Hossain B, Hasan MU. Social vulnerability in the coastal region of Bangladesh: An investigation of social vulnerability index and scalar change effects (2019). International Journal of Disaster Risk Reduction. 2019; doi:10.1016/j.ijdrr.2019.101329.

2. Jamrozik E, Selgelid MJ. Ethics, health policy, and Zika: From emergency to global epidemic? Journal of Medical Ethics. 2018; 44:5.

3. Brazil. Ministry of Health. Monitoramento dos casos de dengue, febre Chikungunya e febre pelo Zika virus até a semana epidemiológica 52 de 2016. 2017; 48:3. URL: http://portalarquivos2.saude.gov.br/images/pdf/2017/abril/06/2017-002-Monitoramento-doscasos-de-dengue-febre-de-chikungunya-e-febre-pelo-v-rus-Zika-ate-a-Semana-Epidemiologica-52-2016.pdf. Accessed 10 Jan 2020.

4. Kawasaki A, Kawamura G, Zin WW. (2019). A local level relationship between floods and poverty: A case in Myanmar. International Journal of Disaster Risk Reduction. 2019; doi:10.1016/j.ijdrr.2019.101348.

5. de Sousa CA, Mendes DDCO, Mufato LF, de Siqueira Queirós P. Zika vírus: conhecimentos, percepções, e práticas de cuidados de gestantes infectadas. Revista Gaúcha de Enfermagem. 2018; doi:10.1590/1983-1447.2018.20180025.

6. Glik DC. Risk Communication for Public Health Emergencies. Annual Review of Public Health. 2007; doi:10.1146/annurev.publhealth.28.021406.144123.

7. World Health Organization. Knowledge, attitudes and practice surveys: Zika virus disease and potential complications: resource pack (No. WHO/ZIKV/RCCE/16.2). 2016; URL: https://apps.who.int/iris/handle/10665/204689. Accessed 10 Oct 2018.

8. Instituto Brasileiro de Geografia e Estatísticas (IBGE). IBGE. Cidades e Estados. 2019; URL: https://www.ibge.gov.br/cidades-e-estados.html?view=municipio. Accessed 7 Nov 2019.

9. Brazil. Ministry of Health \& National Health Council. Resolução CNS 466/2012. Approves regulatory guidelines and standards for research involving human beings. 2012; URL:

https://bvsms.saude.gov.br/bvs/saudelegis/cns/2013/res0466_12_12_2012.html. Accessed 10 Oct 2018.

10. Brazil. Ministry of Health. Portaria $n^{0}-204$, de 17 de fevereiro de 2016. Defines the National Compulsory Notification List of diseases, conditions and public health events in public and private health services throughout the national territory. URL:

http://bvsms.saude.gov.br/bvs/saudelegis/gm/2016/prt0204_17_02_2016.html. Accessed 19 Dec 2019. 
11. Brazil. Ministry of Health. Monitoring dengue, chikungunya fever and acute Zika virus disease cases until Epidemiological Week 52 of 2018. 2019; 40:4. URL: . Access 06 November 2019.https://portalarquivos2.saude.gov.br/images/pdf/2019/setembro/11/BE-arbovirose-22.pdf. Accessed 06 November 2019.

12. Guedes GR, Coutinho RZ, Marteleto L, Pereira WHS, Duarte D. Signifying Zika: heterogeneity in the representations of the virus by history of infection. Cadernos de Saude Publica. 2018; doi:10.1590/0102-311X00003217.

13. World Health Organization. [online] Sexual and reproductive health. Geneva. 2019; URL: https://www.who.int/reproductivehealth/topics/infertility/definitions/en/. Accessed 10 Dec 2019.

14. Mudege NN, Ezeh AC. Gender, aging, poverty and health: Survival strategies of older men and women in Nairobi slums. Journal of Aging Studies. 2009; doi: 10.1016/j.jaging.2007.12.021.

15. Santos BMCD, Coelho FC, Armstrong M, Saraceni V, Lemos C. Zika: an ongoing threat to women and infants. Cadernos de Saude Publica. 2018; doi: 10.1590/0102-311X00038218.

16. Instituto Brasileiro de Geografia e Estatística. [online] Projeção da População 2018: número de habitantes do país deve parar de crescer em 2047. 2018; URL: https://agenciadenoticias.ibge.gov.br/agencia-sala-de-imprensa/2013-agencia-denoticias/releases/21837-projecao-da-populacao-2018-numero-de-habitantes-do-pais-deve-parar-decrescer-em-2047. Accessed 10 Dec 2019.

17. Bolin B., Kurtz L. C. Race, Class, Ethnicity, and Disaster Vulnerability. In: Rodríguez H, Quarantelli EL, Dynes RR, editors. Handbook of Disaster Research. New York: Springer; 2007. p.113-29.

18. Burke RV. Have Lessons Been Learned? Applications from Ebola to Zika Virus. Disaster Medicine and Public Health Preparedness. 2016; 10:(5).

19. Koenig KL., Schultz CH, Runnerstrom MG, Ogunseitan OA. Public Health and Disasters: An Emerging Translational and Implementation Science, Not "Lessons Learned". Disaster medicine and public health preparedness. 2017; 11:5.

20. Liu LE, Dehning M, Phipps A, Swienton RE, Harris CA, Klein KR. Clinical update on dengue, chikungunya, and Zika: what we know at the time of article submission. Disaster medicine and public health preparedness. 2017; 11:3.

21. Possas C, Brasil P, Marzochi MCA, Tanuri A, Martins RM, Marques ETA, Bonaldo MC, Ferreira AGP, Lourenço-de-Oliveira R, Nogueira RMR, Sequeira PC, Marzochi KBF, Homma A. Zika puzzle in Brazil: peculiar conditions of viral introduction and dissemination - A Review. Memórias do Instituto Oswaldo Cruz. 2017; 112:5.

22. Eiser JR, Bostrom A, Burton I, Johnston DM, McClure J, Paton D, White MP. Risk interpretation and action: A conceptual framework for responses to natural hazards. International Journal of Disaster Risk Reduction. 2012; doi:10.1016/j.ijdrr.2012.05.002.

23. Mina MJ, Kula T, Leng Y, Li M, de Vries RD, Knip M, Larman HB. Measles virus infection diminishes preexisting antibodies that offer protection from other pathogens. Science. 2019; 366:6465.

24. Lesser J, Kitron U. A geografia social do zika no Brasil. Estudos Avançados. 2016; 30:88. 
25. Nazer J. Prevención primaria de los defectos congénitos. Revista Médica de Chile. 2004; 132:4.

26. Hodge JG, Corbett A, Repka A, Judd PJ. Zika virus and global implications for reproductive health reforms. Disaster medicine and public health preparedness. 2016; 10:5

27. Olsen JM, Lago TDG, Kalckmann S, Alves MCGP, Escuder MML. Práticas contraceptivas de mulheres jovens: inquérito domiciliar no Município de São Paulo, Brasil. Cadernos de Saúde Pública. 2018; doi: 10.1590/0102-311x00019617.

28. Muller WJ, Mulkey SB. Lessons about early neurodevelopment in children exposed to ZIKV in utero. Nature medicine. 2019; 25:8.

29. Waszak PM, Kasprzycka-Waszak W, Kubanek A. The spread of medical fake news in social mediathe pilot quantitative study. Health Policy and Technology. 2018; 7:2. 